Breaking a habit : The impact of health on turnout and party choice

Rapeli, Lauri

2020-03-01

Rapeli , L , Mattila , V M \& Papageorgiou , A 2020 , ' Breaking a habit : The impact of health on turnout and party choice ' , Party Politics , vol. 26 , no. 2 , pp. 133-142 . https://doi.org/10.1177/135406881775306

http://hdl.handle.net/10138/314224

https://doi.org/10.1177/1354068817753060

unspecified

acceptedVersion

Downloaded from Helda, University of Helsinki institutional repository.

This is an electronic reprint of the original article.

This reprint may differ from the original in pagination and typographic detail.

Please cite the original version. 


\title{
PartyPolitics
}

\section{Breaking a habit: The impact of health on turnout and party choice}

\author{
Lauri Rapeli \\ Åbo Akademi University, Finland \\ Mikko Mattila \\ University of Helsinki, Finland
}

Achillefs Papageorgiou
University of Helsinki, Finland

\begin{abstract}
Turnout and party choice are widely held to be habitual, but little attention has been paid to factors that disrupt the pattern. Good health is an important determinant of political behaviour and a key component in the quality of life. Based on the developmental theory of turnout, we hypothesize that declining health lowers voting propensity over the life course. We employ issue ownership theory to assume that declining health increases the likelihood of voting for leftist parties. Using the British Household Panel Survey data, we show how deteriorating health significantly lowers the propensity to vote, but if a person in poor health votes, she is more likely to support Labour than the Conservatives. As expected by the developmental theory, major life events, such as declining health, affect voting propensity. Results also support issue ownership theory: declining health increases Labour voting which implies that British voters turn to the party that owns the health issue when the issue becomes salient.
\end{abstract}

\section{Keywords}

British Household Panel Survey, party choice, self-rated health, voting

\section{Introduction}

Voting is widely held to be a habit. This view is supported by findings showing that turnout in past elections is a remarkably strong predictor of turnout in subsequent elections (Aldrich et al., 2011; Green and Shachar, 2000). Social-psychological explanations attribute this persistence to feelings of citizen duty and other expressions of emotional attachment to politics (e.g. Campbell et al., 1960), while others emphasize the importance of campaign mobilization which ensures that voters maintain the habit (see also Gerber et al., 2003; e.g. Lake and Huckfeldt, 1998). According to an alternative account, the voting relies on inertia; that is, the habit reinforces itself. This contention is at the heart of the developmental theory of turnout, which focuses on the impact of socialization and first-time voting experiences as the primary forces behind persistent turnout (Plutzer, 2002).

While many studies confirm the habitual nature of voting, surprisingly little attention has been paid to factors that disrupt the pattern. We examine one such factor - personal health. Being in good health is not only a potentially significant determinant of political behaviour, but also a key component in the quality of life for everyone. This insight has led a growing number of scholars to examine personal health as a relatively unexplored determinant of political action (see, e.g., Pacheco and Fletcher, 2015). Their contributions typically analyse personal health from the perspective of resource theory: poor health is expected to diminish the political activity of an individual, much as a lack of any other relevant resource, such as time or social network, would do (Schur et al., 2013: 92; Verba et al., 1995: 16). A possible related mechanism is that health problems may also diminish the psychological capacity

\footnotetext{
Corresponding author:

Lauri Rapeli, The Social Science Research Institute, Åbo Akademi University, ASA A4, Åbo 20500, Finland.

Email: lauri.rapeli@abo.fi
} 
needed to provide the energy and motivation to follow politics and to participate in it (Denny and Doyle, 2007).

Previous studies estimate the negative impact of poor health on voting between 4 and 13 percentage points, controlling for age (see, e.g., Mattila et al., 2017). These findings are valuable, but as they are based on cross-sectional analysis, they merely show that people in poor health have lower voting propensity than people in good health. What remains out of scope is whether a decline in personal health can be associated with a decline in voting propensity. Additionally, the existing literature practically ignores the vital question of party choice.

In this study, we go beyond existing analyses of health and turnout by using the waves 1-18 of the British Household Panel Survey (BHPS), which cover the years from 1991 to 2009 and four British general elections (1992, 1997, 2001 and 2005). The BHPS data enable us to use lagged variables to mitigate potential endogeneity problems in order to provide a more robust understanding of what the impact of health really is on turnout.

We use the BHPS to examine two hypotheses. Based on the developmental theory of turnout, we hypothesize that declining health lowers voting propensity over time. We employ the issue ownership theory to further assume that declining health increases the likelihood of voting for the Labour Party. We find support for both hypotheses. The findings have implications for our understanding of the habitual nature of voting and the actual impact of personal health on turnout and party choice.

\section{Health and turnout}

In the recent wave of studies concerning the impact of health on political behaviour, most studies have focused on voting. The findings suggest that turnout among people who rate their personal health as lower than 'good' is up to 10 percentage points lower than among those with good general health (e.g. Couture and Breux, 2017; Denny and Doyle, 2007; Mattila et al., 2013; Sund et al., 2017), and that the impact of depression is of a comparable magnitude (Ojeda, 2015). The effect of personal health on political action is, however, not always negative, because health problems may also function as a motivator (see also Mattila and Papageorgiou, 2017; Söderlund and Rapeli, 2015; Sund et al., 2017). In terms of voting, poor health nevertheless seems to reduce turnout. While this may not seem surprising, the findings are important in many ways. Firstly, they identify a rather poorly understood factor that clearly has a substantial effect on voting propensity. Even after controlling for the usual suspects among individuallevel determinants (see, e.g., Smets and van Ham, 2013), health still has a sizeable impact on turnout. Secondly, according to a common understanding among scholars working in the cross section between health and politics, health also defines us politically (Carpenter, 2012: 303), which has particular relevance now that Western electorates are rapidly growing older. At the individual level, we are all likely to experience the impact of health either as a result of ageing or even earlier. Personal health is likely to become an even more important determinant of electoral behaviour in the coming years.

Health is typically incorporated into theoretical models of political behaviour through the resource theory approach. In this view, health is treated as a factor similar to time, money and civic skills, all of which affect the likelihood of an individual engaging in politics. Having more of a politically relevant resource, such as health, increases the likelihood of political engagement. Although empirical literature supports the resource model by showing that poor health decreases turnout, the findings are mostly based on cross-sectional data, so we do not know if declining health actually leads people to become more passive voters. With little evidence of possible causality, the current state of the literature is only able to show a turnout gap between different health groups. Consequently, we cannot know whether changes in health status are actually affecting voting propensity or not.

We suggest a slightly different theoretical route. As argued by Plutzer (2002: 41), also the predictors commonly associated with the resource theory make even more sense when they are examined through the inevitable human process of ageing. To this end, Plutzer proposes a developmental theory of voting, which focuses on the forces affecting the habitual nature of voting. It builds on the idea that people settle into patterns of either habitual voting or nonvoting. This inertia of voting, that is, self-reinforcement of an acquired behavioural pattern, is significantly affected by the starting level - the first-time experience of being able to vote. For first-time voters, costs are high and as young people they are often low on relevant resources as well, but after overcoming these hurdles the inertia of voting reinforces their habit election after election (Plutzer, 2002: 42).

When the pattern is established, it is remarkably persistent, as Plutzer (2002) also shows empirically. But even the most stubborn habits can be broken. Plutzer also acknowledges 'temporary disruptions' and mentions unemployment as a condition, which often temporarily lowers the likelihood of voting, because it is 'a major life event that creates immediate demands for one's time and attention' (Plutzer, 2002: 43). In a similar vein, we test the assumption that health has a similar impact. Declining health is certainly for many people a major life event that requires their full attention, and can plausibly be considered a factor that raises the bar for turning out to vote. It seems plausible that experiencing health problems is likely to diminish the time and mental capacity needed for political participation. As Ojeda and Pacheco (2017) have recently shown, depression lowers voting propensity over time and poor self-rated health may have consequences for the formation of voting 
habits in early adulthood. We should therefore expect decline in self-rated health to be associated with lower voting propensity (H1). We assume this relationship to hold even after controlling for relevant sociodemographic determinants.

\section{Health and party choice}

There is more to voting than just turning out. Whether declining health also affects party choice is a vital question. Party choice reflects the fact that voters differ greatly in terms of their needs and preferences, which can also be affected by personal health. On this question, the evidence is scarce, and mostly indirect. Subramanian et al. (2009) used pooled data of three rounds of the European Social Survey from 2002 to 2006 to conclude that people who place themselves in the political left are less healthy. Subramanian et al. (2010) made the same discovery with crosssectional survey data from Japan. A similar analysis by Subramanian and Perkins (2010) from the United States used party identification instead of ideology and found that Republicans are healthier than Democrats. Although inconclusive, the evidence is clear: people who identify themselves as conservatives, or as belonging to the political right, have better health than their liberal, leftist counterparts. The assumed causal direction in these works seems to run from ideology to health, as in ecological studies, which have found that people are healthier in neighbourhoods with conservative majorities (e.g. Cummins et al., 2005). As health scholars search for factors explaining differences in health, they consider political ideology in those terms.

For political scientists, it seems more natural to turn the arrow around and consider variations in health as a predictor for differences in party choice or ideology. We therefore approach health and party choice from a self-interest perspective, which presupposes that all human behaviour is ultimately determined by the attempt to maximize personal gain. Sears and Funk (1991: 58) have claimed that in the field of politics, self-interest will matter only when individuals are highly motivated. If the expected pay-off is low compared to the required investment, self-interest will not affect political behaviour. Health problems could plausibly be a motivator causing people to act in self-interest; the pay-off for a favourable policy outcome is higher, when a person needs the support from the public healthcare sector to cope with health problems.

This logic suggests that people with health problems would be more likely to vote for leftist parties, which are typically more supportive of a large-scale public health sector than conservative parties. This is also compatible with the issue ownership theory, according to which certain parties have managed to create a reputation as being more competent than their competitors in certain political issues. As Petrocik (1996: 826) explains, issue ownership is 'the ability to resolve a problem of concern to voters. It is a reputation for policy and program interests, produced by a history of attention, initiative, and innovation toward these problems'. Parties seek to develop and maintain an image of being more competent than their competitors in a particular field, simultaneously framing that policy field as particularly salient (Lachat, 2014).

In the British context, issue ownership regarding health policy is rather well-documented. Health is overwhelmingly seen as an issue owned by the Labour Party, in comparison to both the Conservatives and the Liberal Democrats (Bellucci, 2006; Green and Hobolt, 2008). In fact, in the analysis by Green and Hobolt (2008), health stands out as the deciding factor for electoral support for Labour. Thus, anyone who in the United Kingdom votes on the basis of the health issue and supports generous health expenditures, is likely to vote for the Labour Party. We therefore assume that declining health increases the likelihood of voting for the Labour Party (H2) ${ }^{1}$.

\section{Analysis}

Our analysis draws on the BHPS, in which a representative sample of respondents was interviewed multiple times between 1991 and 2005. The participants' health condition was measured in the BHPS in every annual wave with the same question: 'Please think back over the last 12 months about how your health has been. Compared to people of your own age, would you say that your health has on the whole been: Very poor, Poor, Fair, Good and Excellent'. The reason that we use a self-rated measure for health and not a more objective one, such as the number of hospital visits, is that self-rated health is a reliable (Fylkesnes and Forde, 1992) and standard way to measure health in most behavioural studies (e.g. Jylhä, 2009). What matters mostly in all these studies, as well as in the present one, is the individual's subjective perception of his/her health. For example, if an individual believes that his health is bad, this can affect his/her behaviour (e.g. voting) regardless of whether his health is 'objectively' bad or not. Our dependent variable is generated by self-declared turnout and party choice from four waves, each corresponding to four different British general elections: 9 April 1992, 1 May 1997, 7 June 2001 and 5 May $2005^{2}$. The data used in the analysis are freely accessible through the UK Data Service (https://discover.ukdataservice.ac.uk/series/?sn=200005).

To assess the effect of health on turnout, we create two variables: one that captures change in health, 'Difference in health (FD)', and one that lags the level of self-reported health, 'Health (Lagged)', by one wave unit (year). Change in the health variable is generated by calculating first differences (FD). After transformation, the FD variable assumes values between 1 and 9. ${ }^{3}$ The lower bound is a value corresponding to individuals whose health was 'Excellent' at wave $w-1$ and deteriorated to 'Very poor' at wave $w$; the upper bound is a value corresponding to 
individuals whose health improved from 'Very poor' at wave $w-1$ to 'Excellent' at wave $w$. The midpoint, 5, stands for cases where health remained unchanged. Including the lagged value of self-reported health in the analysis, we show the effect that past health has on turnout. The main reason for using the lagged value of health is because selfrated health status 'may not be independent of the outcomes we wish to use them to explain' (Pacheco and Fletcher, 2015: 106). For example, individuals may 'justify' their lack of interest in politics by referring to health problems. By using the lagged value of health, we predict the turnout one year later and can circumvent the potential endogeneity problem, which could lead to overestimated coefficient estimates. The lagged health variable can also capture effects that do not take place immediately after the decline in health, but develop more gradually instead.

Our analysis specifies two random effects (RE) panel logit models. In the first one (model 1), we control for voter's age, age ${ }^{\text {squared }}\left(\mathrm{Age}^{2}\right)$, gender, ethnic group ('To which of these ethnic groups do you consider you belong?') and election year. Including age in the analysis is important as it affects both health and turnout. $\mathrm{Age}^{2}$ controls for the non-linear effect of age on turnout. Ethnicity ${ }^{4}$ is added in the equation as a potentially important factor affecting turnout. Lastly, given that turnout rates are not the same from one election to the next, we also include dummies for each election year. In the second model, we add two more controls: education and marital status (model 2). In general, the first model includes variables that cannot be affected by health. The same is not necessarily true for education and marital status as one can expect that there is a reciprocal relationship between health and these two variables.

The rationale behind the RE specification is that most variation of our time-varying regressors is between- rather than within-panels variation (see Online Appendix B). ${ }^{5}$ This is an important point to take into account given that fixed effects (FE) estimators rely on within variation. Yet, since it is beyond the scope of our analysis to make a choice $^{6}$ between FE and RE, we run the models also assuming a FE specification ${ }^{7}$ (Online Appendix C). To account for unequal correlation of errors under the RE specification, we use robust standard errors throughout the analyses. The coefficient estimates from RE logit on panel data are shown separately for models 1 and 2 in Table 1 .

The very high rho reported in model $1(0.95)$ and model 2 (0.93) verifies our initial intuition that the panel-level variance component is important and therefore cannot be ignored. Before discussing the estimates of our main independent variables, it can be seen that most coefficient estimates of the control variables are towards the anticipated order in both models 1 and 2. Age has a curvilinear effect on turnout meaning that the likelihood of voting increases as one gets older until a point after which it begins to decrease. In comparison to those identifying themselves as British, ethnicity does not seem to play a significant role
Table I. Turnout: RE logit models.

\begin{tabular}{|c|c|c|}
\hline $\begin{array}{l}\text { Dependent variable: } \\
\text { Turnout in 1992, 1997, } \\
2001,2005 \text { elections }\end{array}$ & Model I & Model 2 \\
\hline \multicolumn{3}{|l|}{ Independent variables } \\
\hline $\begin{array}{l}\text { Difference in health (FD) } \\
\text { Level of health (lagged) }\end{array}$ & $0.385 * * *(0.076)$ & $0.280 * * *(0.07 I)$ \\
\hline Very poor & $-3.182 * * *(0.517)$ & $-2.297 * * *(0.476)$ \\
\hline Poor & $-2.103 * * *(0.310)$ & $-1.400 * * *(0.288)$ \\
\hline Fair & $-0.962 * * *(0.217)$ & $-0.543 * *(0.201)$ \\
\hline Good & $-0.517 * *(0.160)$ & $-0.337 *(0.151)$ \\
\hline Age & $0.559 * * *(.032)$ & $0.438 * * *(0.029)$ \\
\hline $\mathrm{Age}^{2}$ & $-0.003 * * *(0.000)$ & $-0.002 * * *(0.000)$ \\
\hline \multicolumn{3}{|c|}{ - } \\
\hline Male & $-0.219(0.194)$ & $-0.372 *(0.174)$ \\
\hline \multicolumn{3}{|l|}{$\begin{array}{l}\text { Ethnic group } \\
\text { membership: }\end{array}$} \\
\hline Irish & $1.104 *(.518)$ & I.379** (0.476) \\
\hline Welsh & $0.166(0.239)$ & $0.185(0.232)$ \\
\hline Scottish & $0.156(0.208)$ & $0.142(0.198)$ \\
\hline Caucasian background & $0.484(0.404)$ & $0.258(0.403)$ \\
\hline Mixed background & $-0.334(0.634)$ & $-0.087(0.623)$ \\
\hline $\begin{array}{l}\text { Brit Caribbean/African/ } \\
\text { Asian } \\
\text { Education: }\end{array}$ & $-0.182(0.593)$ & $-0.294(0.609)$ \\
\hline Degree & & $5.25 \mathrm{I} * * *(0.394)$ \\
\hline Diploma & & $3.854 * * *(0.416)$ \\
\hline A-level & & $4.030 * * *(0.340)$ \\
\hline O-level & & $2.083 * * *(0.267)$ \\
\hline CSE & & $0.899 *(0.455)$ \\
\hline \multicolumn{3}{|l|}{ Marital status: } \\
\hline Married & & $1.363 * * *(0.15 \mathrm{I})$ \\
\hline \multicolumn{3}{|l|}{ Election year: } \\
\hline 1997 & $-1.612^{* * *}(0.193)$ & $-1.644 * * *(0.186)$ \\
\hline 2001 & $-3.359 * * *(0.243)$ & -3.39 I*** $(0.230)$ \\
\hline 2005 & $-4.720 * * *(0.298)$ & $-4.783 * * *(0.282)$ \\
\hline$N$ & 27,376 & 27,157 \\
\hline Sigma_u & $7.732(0.35 I)$ & $6.699(0.288)$ \\
\hline Rho & $0.948(0.004)$ & $0.932(0.005)$ \\
\hline
\end{tabular}

Note: RE: random effects; FD: first differences. Reference categories: 'Excellent' (Health (Lagged)); 'Female' (gender); 'British' (ethnic group membership); 'No qualification' (education); 'Unmarried' (marital status); '1992' (election year). Parenthesized entries are robust standard errors. $*_{p}<0.05 ; * * p<0.01 ; * * *_{p}<0.001$.

in turning out to vote, other than in the case of those who report their ethnicity as Irish. With regard to education, having any type of qualification versus having 'No qualification' increases the log odds of turning out to vote. Also, females are more likely to turn out to vote compared to males (statistically significant result only in model 2) and married compared to unmarried. In reference to general elections in 1992, estimates for 1997, 2001 and 2005 are all negative, quite large and highly significant. This result makes sense; in 1992, the official turnout was around $78 \%$, but in the next three general elections, it declined quite dramatically: In 1997, it went down to $71 \%$; in 2001 , it slumped to $59 \%$; and in 2005, remained as low as $61 \%$. 


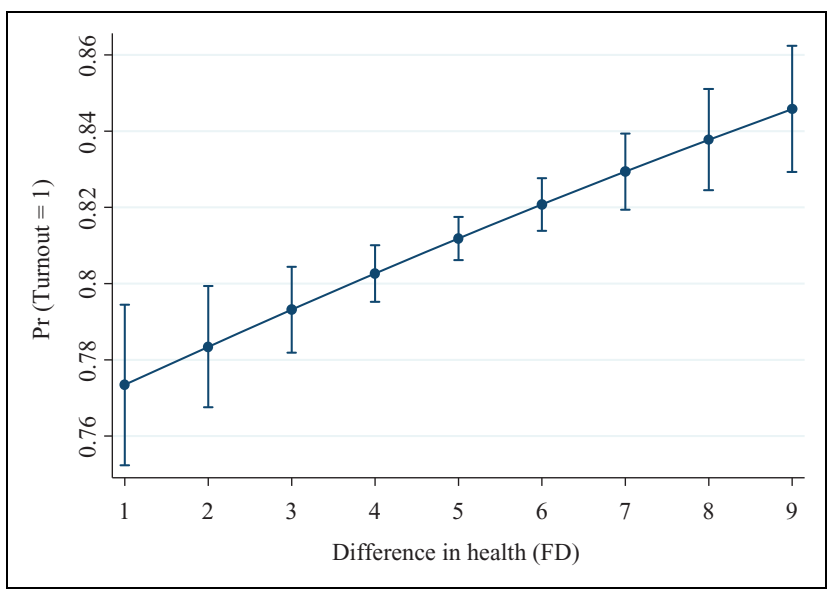

Figure I. Turnout: Predictive margins of 'Difference in health (FD)' with $95 \%$ Cls. Note: I, 'Health deteriorated substantially'; 2, 'Health deteriorated a lot'; 3 , 'Health deteriorated somewhat'; 4, 'Health deteriorated a little'; 5 , 'Health remained unchanged'; 6, 'Health improved a little'; 7, 'Health improved somewhat'; 8, 'Health improved a lot'; 9, 'Health improved substantially'. All margins are significant with $p<0.00 \mathrm{I}$. FD: first differences; $\mathrm{Cl}$ : confidence interval.

Next, we turn attention to our two main independent variables: First, it can be seen that the variable capturing change in health, 'Difference in health (FD)', is highly significant $(p<0.000)$ and positive. This means that as health declines between two successive years, the likelihood of turning out to vote also decreases. Figure 1 shows this by graphing the margins ${ }^{8}$ for the change variable. As can be seen, the average probability of turning out to vote increases as one moves declining (1-4 on the $x$-scale) to stable (5) and improving health (6-9).

With regard to our second main independent variable, the lagged level of health, the coefficients are significant in both models 1 and 2. More precisely, the log odds of turning out to vote decrease by $0.517(0.337)$ when health deteriorates from 'Excellent' to 'Good'; 0.962 (0.543) when health deteriorates from 'Excellent' to 'Fair'; 2.103 (1.400) when health deteriorates from 'Excellent' to 'Poor'; and 3.182 (2.297) when health deteriorates from 'Excellent' to 'Very poor' (parenthesized entries are estimates for model 2). Figure 2 shows the respective margins.

As can be seen, the margins increase monotonically as health improves from 'Very Poor' to 'Poor' to 'Fair' to 'Good' to 'Excellent'. This is also in line with previous studies (e.g. Denny and Doyle, 2007; Mattila et al., 2013). One might ask: Are people with poor health less likely to vote because of their health condition or because of de facto disenfranchisement (e.g. difficulties that people with disabilities face in accessing the polling stations)? In Britain, people with disabilities who have difficulties going to the polling station can vote by post or proxy. Also, electoral officers are legally obliged to make adjustments to the polling station so to facilitate the accessibility of

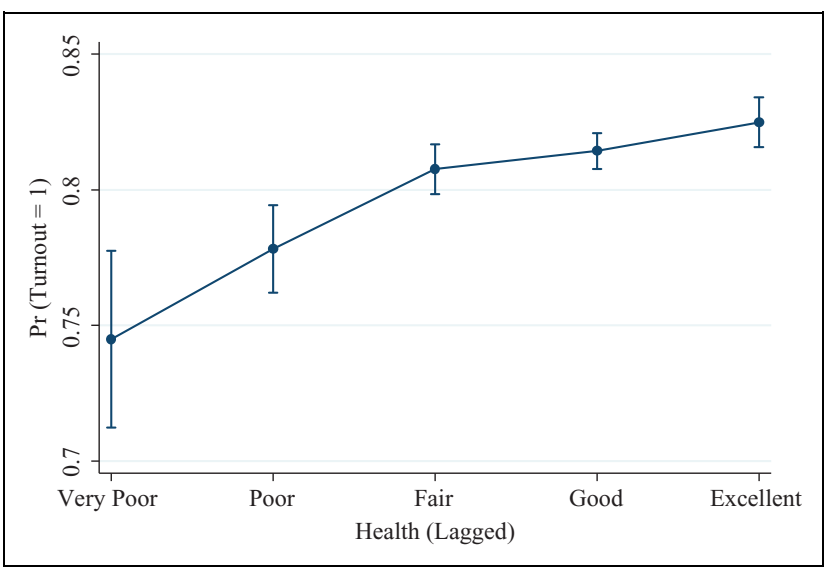

Figure 2. Turnout: Predictive margins of 'Health (Lagged)' with $95 \%$ Cls. Note: All margins are significant with $p<0.000$ I. $\mathrm{Cl}$ : confidence interval.

people with disabilities, for example, provide auxiliary aids or tactile voting device and a large print display version of the ballot paper for the blind and visual impaired. Given the former arrangements, our results are likely to reflect the real effect of health on turnout, rather than the effect related to the absence of voting facilitation mechanisms.

When voters turn out to vote, does their health condition affect their party choice? To answer this question, we repeat the above analysis replacing the response variable in each model with a dummy where 1 signifies voting for a certain party and 0 for the rivals. For example, the dummy 'Voted for Labour' assumes the value of 1 when the respondent voted for Labour and 0 when voted for either the Conservatives or the Liberal Democrats. Results for model 1 and model 2 are calculated separately for Labour, Conservatives and Liberal Democrats in Table 2.

As we can see from Table 2, control variables behave in the complete opposite way for Labour and Conservatives (in both model 1 and model 2). Irish, Welsh, Scottish and voters with mixed ethnic background are more (less) likely to vote for Labour (Conservatives) than those classifying themselves as British. People with no qualification are more (less) likely to vote for Labour (Conservatives) than those with educational qualification. Also, unmarried people are more (less) likely to vote for Labour (Conservatives) compared to married ones. Lastly, compared to 1992, voters were more (less) likely to vote for Labour (Conservatives) in 1997, 2001 and 2005 elections. For the Liberal Democrats, other than educational qualification, gender and election year, all other variables including our main independent variables 'Difference in health (FD)' and 'Health (Lagged)' do not have a statistically significant effect.

Most importantly, regarding the effect of 'Difference in health (FD)' and 'Health (Lagged)' on voting for Labour and Conservatives, we notice results that are in line with our hypothesis: the variable measuring change in health is 
Table 2. Party choice: RE logit models.

\begin{tabular}{|c|c|c|c|c|c|c|}
\hline \multirow{2}{*}{$\begin{array}{l}\text { Independent } \\
\text { variables: }\end{array}$} & \multicolumn{2}{|c|}{ Voted Labour Party } & \multicolumn{2}{|c|}{ Voted Conservative Party } & \multicolumn{2}{|c|}{ Voted Liberal Democrats } \\
\hline & Model I & Model 2 & Model I & Model 2 & Model I & Model 2 \\
\hline $\begin{array}{l}\text { Difference in } \\
\text { health (FD) }\end{array}$ & $-0.285 * * *(0.060)$ & $-0.244 * * *(0.060)$ & $0.309 * * *(0.067)$ & 0.30 I*** $(0.067)$ & $0.057(0.052)$ & $0.015(0.052)$ \\
\hline \multicolumn{7}{|l|}{ Health (Lagged) } \\
\hline Very poor & $2.120 * * *(0.391)$ & $1.803 * * *(0.394)$ & $-2.256 * * *(0.418)$ & $-2.112 * * *(0.420)$ & $-0.7 \mid 4^{*}(0.354)$ & $-0.468(0.36 I)$ \\
\hline Poor & $1.597 * * *(0.234)$ & $1.303 * * *(0.233)$ & $-1.719 * * *(0.269)$ & $-1.597 * * *(0.268)$ & $-.357(0.200)$ & $-0.105(0.201)$ \\
\hline Fair & $0.988 * * *(0.160)$ & $0.787 * * *(0.160)$ & $-1.270 * * *(0.183)$ & $-1.214^{* * *}(0.183)$ & $0.037(0.135)$ & $0.228(0.135)$ \\
\hline Good & $0.382 * *(0.118)$ & $0.305 *(0.118)$ & $-.644 * * *(0.131)$ & $-0.639 * * *(0.131)$ & $0.139(0.105)$ & $0.232 *(0.104)$ \\
\hline Age & $0.032(0.020)$ & $0.024(0.022)$ & $-0.028(0.023)$ & $-0.026(0.025)$ & $-0.013(0.016)$ & $0.001(0.017)$ \\
\hline $\mathrm{Age}^{2}$ & $-0.001 * *(0.000)$ & $-0.001 * * *(0.000)$ & $0.001 * * *(0.000)$ & $0.001(0.000)$ & $-0.000(0.000)$ & $-0.000(0.000)$ \\
\hline \multicolumn{7}{|l|}{ Gender: } \\
\hline Male & $0.222(0.158)$ & $0.396 *(0.157)$ & $-0.081(0.180)$ & $-0.151(0.178)$ & $-0.144(0.114)$ & $-0.256^{*}(0.113)$ \\
\hline \multicolumn{7}{|l|}{$\begin{array}{l}\text { Ethnic group } \\
\text { membership }\end{array}$} \\
\hline Irish & $2.359 * *(0.736)$ & $2.344 * *(0.730)$ & $-2.260 *(0.948)$ & $-2.066 *(0.880)$ & $-0.910(0.588)$ & $-I .15 I(0.607)$ \\
\hline Welsh & I.104*** $(0.260)$ & $1.057 * * *(0.262)$ & $-1.320 * * *(0.307)$ & $-1.322 * * *(0.304)$ & $-0.321(0.228)$ & $-0.226(0.229)$ \\
\hline Scottish & $0.56 I *(0.255)$ & $0.568 *(0.255)$ & $-I .56 I * * *(0.29 I)$ & $-1.530 * * *(0.291)$ & $0.455^{*}(0.205)$ & $0.390(0.204)$ \\
\hline $\begin{array}{l}\text { Caucasian } \\
\text { background }\end{array}$ & $0.06 \mathrm{I}(0.377)$ & $0.113(0.381)$ & $0.419(0.431)$ & $0.373(0.439)$ & $-0.539(0.340)$ & $-0.580(0.34 I)$ \\
\hline $\begin{array}{l}\text { Mixed } \\
\text { background }\end{array}$ & $3.042 * * *(0.705)$ & $2.669 * * *(0.694)$ & $-3.132 * * *(0.856)$ & $-2.738 * *(0.826)$ & $-0.456(0.5 \mid 5)$ & $-0.456(0.517)$ \\
\hline $\begin{array}{r}\text { Brit Caribbean/ } \\
\text { African/Asian }\end{array}$ & $0.519(0.658)$ & $0.443(0.655)$ & $-0.929(1.048)$ & $-0.874(1.035)$ & $-0.012(0.555)$ & $0.047(0.568)$ \\
\hline \multicolumn{7}{|l|}{ Education } \\
\hline Degree & & -3.34 I $* * *(0.282)$ & & $0.387(0.3 \mid 2)$ & & $2.663 * * *(0.199)$ \\
\hline Diploma & & $-3.000 * * *(0.324)$ & & I.57| **** (0.365) & & $1.595 * * *(0.237)$ \\
\hline A-level & & $-3.183 * * *(0.26 I)$ & & $2.072 * * *(0.295)$ & & I.5II **** (0.183) \\
\hline O-level & & $-2.785 * * *(0.234)$ & & $2.218 * * *(0.257)$ & & $0.885^{* * *}(0.165)$ \\
\hline CSE & & $-1.604 * *(0.466)$ & & $1.286 *(0.510)$ & & $0.402(0.382)$ \\
\hline \multicolumn{7}{|l|}{ Marital status } \\
\hline Married & & $-0.499 * * *(0.134)$ & & $0.579 * * *(0.160)$ & & $-0.082(0.109)$ \\
\hline \multicolumn{7}{|l|}{ Election year } \\
\hline 1997 & $2.057 * * *(0.105)$ & $2.314 * * *(0.110)$ & $-2.06 \mathrm{I} * * *(.117)$ & $-2.139 * * *(0.120)$ & $-0.246 * *(0.094)$ & $-0.424 * * *(0.095)$ \\
\hline 2001 & $2.065 * * *(0.117)$ & $2.498 * * *(0.125)$ & $-2.381 * * *(.137)$ & $-2.521 * * *(0.143)$ & $0.037(0.097)$ & $-0.253^{*}(0.099)$ \\
\hline 2005 & $1.206 * * *(0.139)$ & $1.862 * * *(0.151)$ & $-2.136 * * *(.160)$ & $-2.349 * * *(0.169)$ & $0.689 * * * *(0.114)$ & $0.240 *(0.118)$ \\
\hline$N$ & 19,572 & 19,478 & 19,572 & 19,478 & 19,572 & 19,478 \\
\hline Sigma_u & $6.089(0.196)$ & $5.959(0.191)$ & $6.707(0.236)$ & 6.557 (0.229) & $3.694(0.122)$ & 3.597 (0.1 19) \\
\hline Rho & $0.919(0.005)$ & $0.915(0.005)$ & $0.932(0.004)$ & $0.929(0.005)$ & $0.806(0.010)$ & $0.797(0.011)$ \\
\hline
\end{tabular}

Note: RE: random effects; FD: first differences. Reference categories: 'Excellent' (Health (Lagged)); 'Female' (gender); 'British' (ethnic group membership); 'No qualification' (education); 'Unmarried' (marital status); '1992' (election year). Parenthesized entries are robust standard errors.

$* p<0.05 ; * * p<0.01 ; * * p<0.001$.

negative and highly significant in the case of Labour, but positive and highly significant in the case of Conservatives.

As we can see in Figure 3, the average probability of turning out to vote for Labour decreases monotonically as one moves from 1 to 9 . In other words, the probability of voting for Labour decreases (increases) as health improves (deteriorates). The exact opposite is observed for voters of the Conservative Party, whereas the pattern of results resembles that of Figure 1, that is, the probability of voting for the Tories increase (decrease) as health improves (deteriorates).

Regarding the level of health, we notice that in reference to 'Excellent' health, coefficient estimates increase in the case of Labour Party and decrease in the case of Conservative Party.

As can be seen in Figure 4, the average probability of voting for Labour decreases monotonically as one moves from 'Very poor' to 'Excellent' health. In other words, people with poor health are more likely to vote for Labour than people in a good health condition. The exact opposite is true for voters of the Conservative Party. These results offer support to our hypothesis that voters with poor health are more inclined to cast a vote for a left-wing party, such as Labour, that traditionally supports strong public welfare policies and pledges to ensure the affordability of the National Health System. 


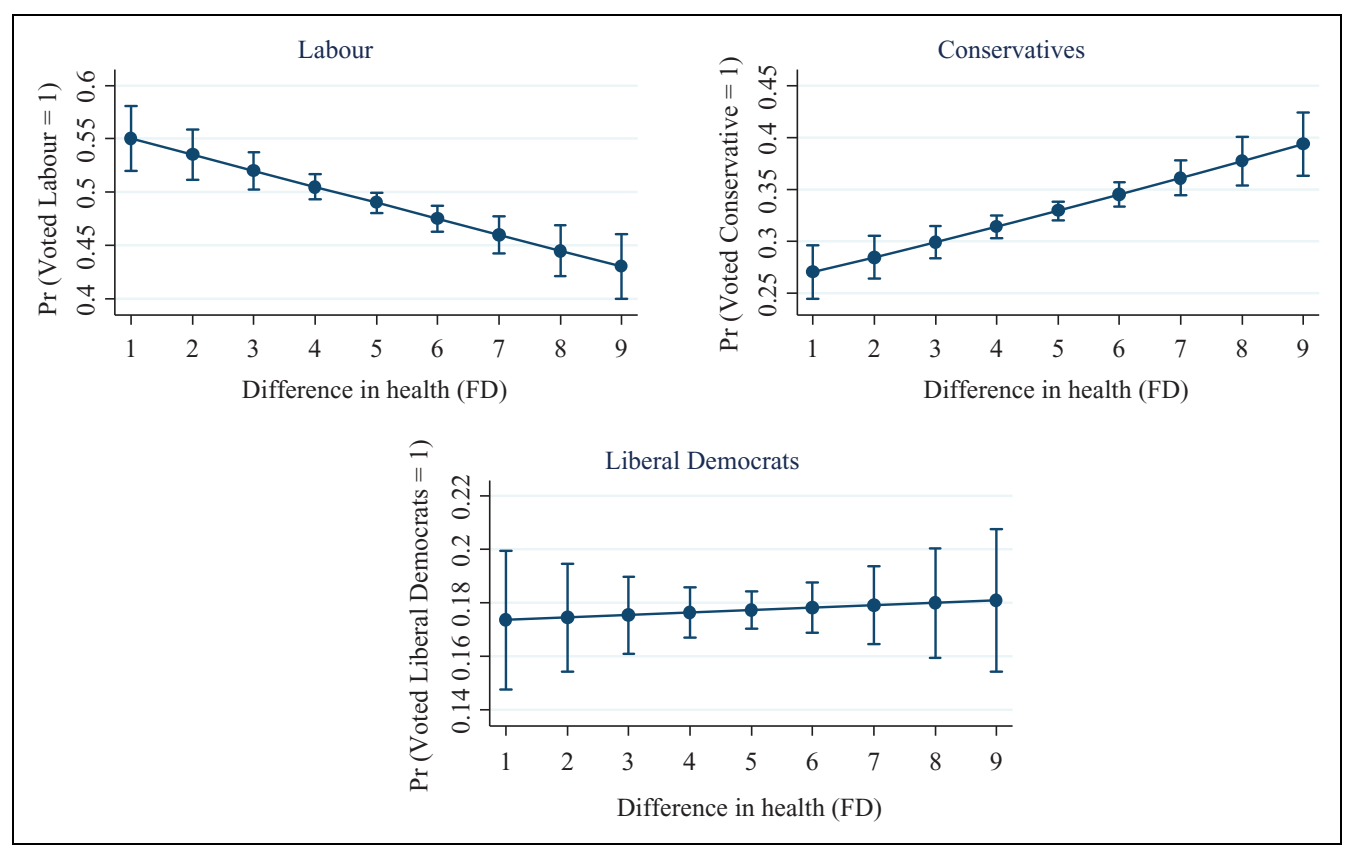

Figure 3. Party choice: Predictive margins of 'Difference in health (FD)' with $95 \%$ Cls. Note: I, 'Health deteriorated substantially'; 2, 'Health deteriorated a lot'; 3, 'Health deteriorated somewhat'; 4, 'Health deteriorated a little'; 5, 'Health remained unchanged'; 6, 'Health improved a little'; 7, 'Health improved somewhat'; 8, 'Health improved a lot'; 9, 'Health improved substantially'. All margins are significant with $p<0.001$. FD: first differences; $\mathrm{Cl}$ : confidence interval.

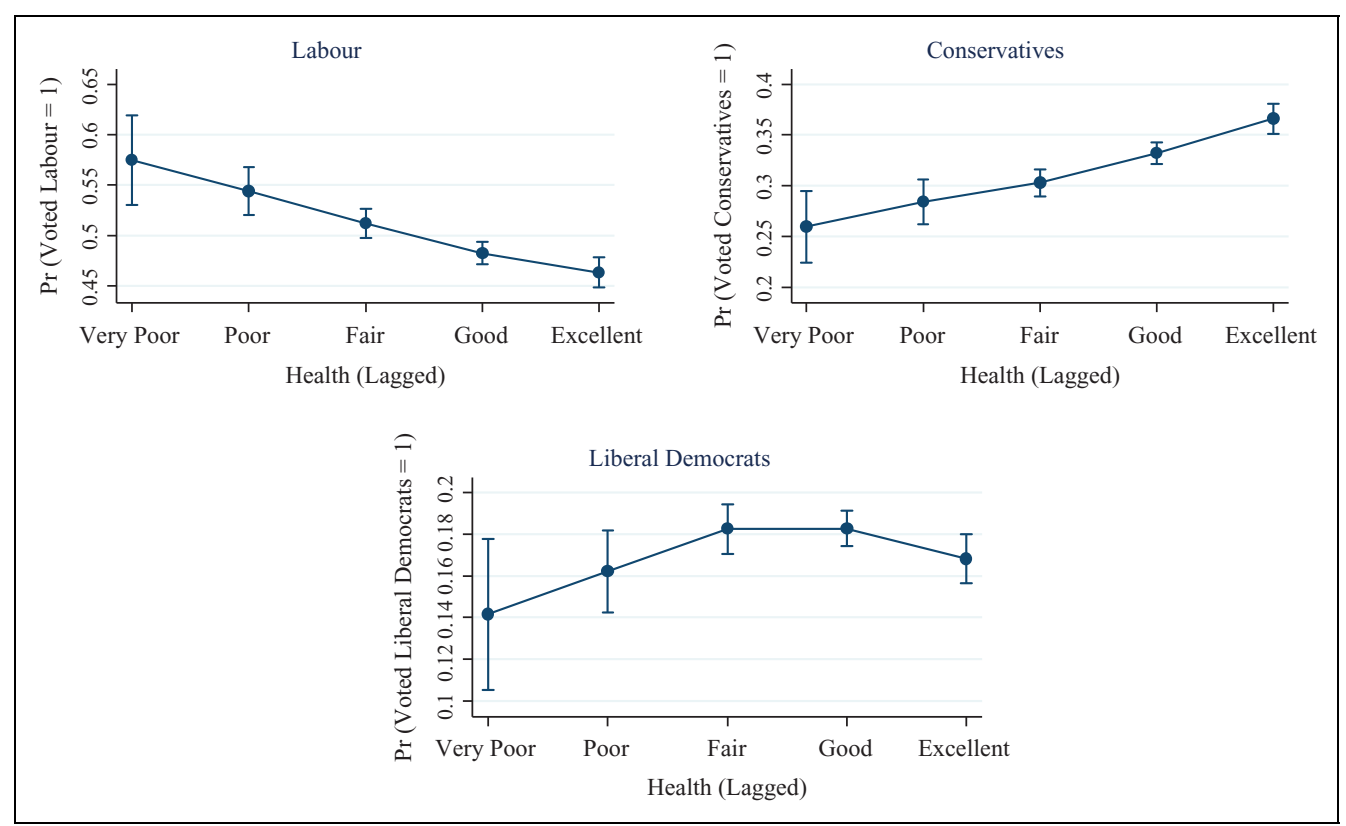

Figure 4. Party choice: Predictive margins of 'Health (Lagged)' with $95 \%$ Cls. Note: All margins are significant with $p<0.00 \mathrm{I}$. $\mathrm{Cl}$ : confidence interval.

\section{Conclusions}

We have examined how health is related to turnout and party choice in Britain. The BHPS enables us to avoid some of the problems affecting previous studies using crosssectional survey data. With panel data, we could analyse how, not only levels of health, but also changes in health affect voting. Furthermore, with lagged variables, we were able to get around the potential endogeneity problems of the health measures.

The results show clearly how both turnout and party choice are affected by voter's health condition. First, our 
results confirm hypothesis 1 , which was based on findings from many cross-sectional analyses that people in poor health are less likely to turn out to vote. However, the results also show how changes in health are significant: A decline in self-reported health predicts a lower propensity to vote. This is an important finding when we try to ascertain the causal linkages between health and political participation. This finding is also consistent with the observation that depression is associated with diminished voting propensity over time (Ojeda and Pacheco, 2017).

The second hypothesis concerned the impact of health decline on party choice. Based on the self-interest framework and issue ownership theory, we assumed that deteriorating health leads citizens to support more left-wing parties as these parties are more likely to favour strong public healthcare services and, in general, stronger public measures to help people in need. Consequently, we hypothesized that poor health can be associated with increased likelihood to support the Labour Party. The findings confirm this assumption: those in poor health are more likely to vote for Labour candidates. Also, decline in health was associated with stronger Labour support. The picture for the Conservative Party was totally opposite. Good health and improvements in health both lead to support for the Conservative candidates. For support of the Liberal Democrats, we were not able to find health determinants.

In terms of the developmental theory of voting, the implications are that major life events, such as deteriorating health, seem to affect voting propensity, as especially Plutzer (2002) has suspected. We also find evidence corroborating the relevance of issue ownership theory in explaining party choice. That declining health increases Labour voting implies that British voters turn to the party that owns the health issue when health becomes a salient issue to them. Overall, the findings provide a confirming message for the current wave of studies looking at the impact of health on political behaviour: Health matters for voting behaviour. Not only are people in poor health less likely to vote, also changes for the worse in personal health lower turnout. Contextual factors could, nevertheless, also matter. Health policy ownership is not as clear between competing parties in all countries and cross-national differences in, for example, voting facilitation mechanisms might cause variation in the disruptive force of declining health (see also Wass et al., 2017).

\section{Declaration of Conflicting Interests}

The author(s) declared no potential conflicts of interest with respect to the research, authorship, and/or publication of this article.

\section{Funding}

The author(s) disclosed receipt of the following financial support for the research, authorship, and/or publication of this article: This study is part of the project "Health and political engagement," funded by the Academy of Finland (grant number 1266844).

\section{Supplemental material}

Supplementary material for this article is available online.

\section{Notes}

1. We exclude the Scottish Nationalist Party and Plaid Cymru from our analyses because of their regional nature.

2. Each of the four general British elections was covered in the survey by more than one wave (panel): For example, the general British election of May 1997 was covered by the 7th, 8 th, 9th and 10th wave. One problem that we noticed is that in some cases where the same person was asked whether he/she voted in the last general elections, he/she provided conflictual answers from wave to wave although the question was referring to the same general British election. To increase credibility in our results, we decided to remove from the analysis those respondents who gave conflictual answers regarding their turnout in the same British general election.

3. The initial range $[-4,4]$ has been transformed to $[1,9]$.

4. To deal with the large number of missing cases in this variable (423,490 missing as opposed to 32,702 non-missing), we replaced the missing values with previous non-missing values. When a respondent changed the ethnic group he/she identifies with between two non-consecutive waves, we replaced the missing values with previous non-missing values using as cut point the wave when the respondent changed his/ her ethnic group membership. So, for example, if a respondent identified as 'Irish' in the 1st wave and as 'British' in the 7 th one, missing values were replaced with the value of 'Irish' until the 7th wave and with 'British' from the 7th until the 18th wave. The new variable for ethnic group membership finally numbered 428,724 non-missing values as opposed to 27,468 missing ones.

5. When setting the random effects (RE) logit models, we maintained the default approximation of the log likelihood (adaptive Gauss-Hermite quadrature points) correcting for the number of integration points (See Online Appendix A).

6. Scholars are divided between RE and fixed effects (FE; see Baltagi (2008: 21-22)). An interesting discussion on choosing between RE and FE is also made in Clark and Linzer (2014).

7. We also check for robustness by fitting a linear model with $\mathrm{RE}$ and a population average (PA) specification (Online Appendix C).

8. To avoid repetition, we do not present margins of model 1 that are essentially identical with model 2 .

9. http://www.stata.com/manuals13/xtquadchk.pdf.

10. We also perform the same analysis switching to non-adaptive Gauss-Hermite quadrature retaining each time the same number of integration points when assumed adaptive quadrature. Scores of relative differences indicate that nonadaptive quadrature yields less robust results. 
11. A comparison between the different model specifications indicates that small number of quadrature points result in overestimated coefficients for all variables included in the model.

12. This is true even if one introduces dummies for each observation and corrects for error correlation over time for the same respondent in the pooled logit.

13. Same holds when the dependent variable is direction of voting.

\section{References}

Aldrich J, Montgomery J and Wood W (2011) Turnout as a habit. Political Behavior 33(4): 535-563.

Baltagi HB (2008) Econometric Analysis of Panel Data. Chichester: John Wiley \& Sons.

Bellucci P (2006) Tracing the cognitive and affective roots of 'party competence': Italy and Britain, 2001. Electoral Studies 25(3): 548-569.

Campbell A, Converse PE, Miller WE, et al. (1960) The American Voter. New York: John Wiley \& Sons.

Carpenter D (2012) Is health politics different? Annual Review of Political Science 15: 287-311.

Clark ST and Linzer AD (2014) Should I use fixed or random effects? Political Science Research Methods 3(2): 399-408.

Couture J and Breux S (2017) The differentiated effects of health on political participation. European Journal of Public health 27(4): 599-604.

Cummins S, Stafford M, Macintyre S, et al. (2005) Neighbourhood environment and its association with self-rated health: evidence from Scotland and England. Journal of Epidemiology \& Community Health 59(3): 207-213.

Denny K and Doyle O (2007) Analysing the relationship between voter turnout and health in Ireland. Irish Medical Journal 100(8): 56-58.

Fylkesnes K and Forde OH (1992) Determinants and dimensions involved in self-evaluation of health. Social Science and Medicine 35(3): 271-279.

Gerber AS, Green DP and Shachar R (2003) Voting may be habitforming: evidence from a randomized field experiment. American Journal of Political Science 47(3): 540-550.

Green D and Shachar R (2000) Habit formation and political behaviour: evidence of consuetude in voter turnout. British Journal of Political Science 30(4): 561-573.

Green J and Hobolt SB (2008) Owning the issue agenda: party strategies and vote choices in British elections. Electoral Studies 27(32): 460-476.

Jylhä M (2009) What is self-rated health and why does it predict mortality? Towards a unified conceptual model. Social Science \& Medicine 69(3): 307-316.

Lachat R (2014) Issue ownership and the vote: the effects of associative and competence ownership on issue voting. Swiss Political Science Review 20(4): 727-740.

Lake RL and Huckfeldt R (1998) Social capital, social networks, and political participation. Political Psychology 19(3): 567-584.
Mattila M, Rapeli L, Wass H and Söderlund P (2017) Health and Political Engagement. Abingdon: Routledge.

Mattila M and Papageorgiou A (2017) Disability, perceived discrimination and political participation. International Political Science Review 38(5): 505-519.

Mattila M, Söderlund P, Wass H, et al. (2013) Healthy voting: the effect of self-reported health on turnout in 30 countries. Electoral Studies 32(4): 886-891.

Ojeda C (2015) Depression and political participation. Social Science Quarterly 96(5): 1226-1243.

Ojeda C and Pacheco J (2017) Health and voting in young adulthood. British Journal of Political Science (In Press).

Pacheco J and Fletcher J (2015) Incorporating health into studies of political behavior evidence for turnout and partisanship. Political Research Quarterly 8(1): 104-116.

Petrocik J (1996) Issue Ownership in Presidential Elections, with a 1980 Case Study. American Journal of Political Science 40(3): 825-850.

Plutzer E (2002) Becoming a habitual voter: inertia, resources, and growth in young adulthood. The American Political Science Review 96(1): 41-56.

Schur L, Kruse D and Blanck P (2013) People with Disabilities, Sidelined or Mainstreamed? Cambridge: Cambridge University Press.

Sears D and Funk CL (1991) The role of self-interest in social and political attitudes. In: Zanna M (ed), Advances in Experimental Social Psychology, Vol. 24. Orlando: Academic Press, pp. $1-91$.

Smets K and van Ham C (2013) The embarrassment of riches? A meta-analysis of individual-level research on voter turnout. Electoral Studies 32(2): 344-359.

Subramanian SV, Huijts T and Perkins JM (2009) Association between political ideology and health in Europe. European Journal of Public Health 19(5): 455-457.

Subramanian SV, Hamano T, Perkins JM, et al. (2010) Political ideology and health in Japan: a disaggregated analysis. Journal of Epidemiology \& Community Health 64(9): 838-840.

Subramanian SV and Perkins JM (2010) Are republicans healthier than democrats? International Journal of Epidemiology 39(3): 930-931.

Sund R, Lahtinen H, Wass H, et al. (2017) How voter turnout varies between different chronic conditions? Journal of Epidemiology \& Community Health 71(5): 475-479.

Söderlund P and Rapeli L (2015) In sickness and in health: assessing health effects on political participation in the Nordic countries. Politics and Life Sciences 34(1): 28-43.

Verba S, Lehman Schlozman K and Brady HE (1995) Voice and Equality, Civic Voluntarism in American Politics. Cambridge: Harvard University Press.

Wass H, Mattila M, Rapeli L, et al. (2017) Voting while ailing? The effect of voter facilitation policies on health differences in turnout. Journal of Elections, Public Opinion and Parties 27(4): 503-522. 


\section{Author biographies}

Lauri Rapeli is the Research Director (acting) at the Social Science Research Institute in Åbo Akademi University. His recent work has been published in journals such as European Journal of Political Research, Government and Opposition and Journal of Elections, Public Opinion and Parties.

Mikko Mattila is a Professor of Political Science at the University of Helsinki. He has published articles in leading peer- reviewed journals, such as British Journal of Political Science, Electoral Studies, European Journal of Political Research and West European Politics.

Achillefs Papageorgiou is a Postdoctoral Researcher at the Department of Political Science in the University of Helsinki. His research has appeared in journals such as Acta Politica, Electoral Studies, International Political Science Review and Scandinavian Political Studies. 